CASE REPORTS

\title{
Carcinoma of the gastric antrum in identical twins
}

\author{
FrANK I. LEE \\ M.B., M.R.C.P. \\ Victoria Hospital, Blackpool
}

THis paper describes twin men, presumably but not unequivocally monozygotic, who developed carcinoma of the gastric antrum aged 57 and 59 years respectively.

\section{Case 1}

J. E. born 19 May, 1909. This man presented in August 1968 with a 2-month history of anorexia and $28 \mathrm{lb}$ weight-loss.

On examination there were no abnormal signs and two barium meal examinations showed smoothness of the antrum with no definite evidence of carcinoma. Gastroscopy showed nodularity and rigidity of the posterior wall of the antrum. His blood group was $\mathbf{O}$ Rhesus-negative. Laparotomy revealed a typical carcinomatous ulcer of the antrum which was resected; a Billroth 1 gastrectomy was performed. There was no evidence of metastases. Histologically the lesion was an adenocarcinoma.

Twenty years previously he had had troublesome epigastric pain after meals. This lasted several months and he had a haematemesis. He had a barium meal and was told that this showed a duodenal ulcer. The symptoms cleared and he did well, having no further dyspepsia. The records and X-rays relating to this illness are no longer available.

The patient's wife mentioned that she thought his identical twin brother had died from a 'tumour of the bowel' and for this reason case records, X-rays and microscope slides were obtained from the hospital which he had attended.

\section{Case 2}

C. E. born 19 May, 1909; presented in April 1966 with a 2-month history of anorexia, weight loss and occasional vomiting which had relieved a heavy sensation in the epigastrium. He gave a history of mild recurrent dyspepsia for $7-8$ years.

On examination he was thin and there was epigastric tenderness. His blood group was $\mathbf{O}$ Rhesusnegative. A barium meal examination showed a 'fairly rigid filling defect in the pyloric antrum, probably intrinsic carcinoma'. A palliative Polya gastrectomy was performed and at laparotomy enlarged left gastric lymph nodes and a few seedlings over the serosa of the cardiac end of the stomach were noted. The pathologist reported a huge malignant ulcer of the antrum and histologically this was an adenocarcinoma. He did well postoperatively initially, but after 18 months died at home from presumed recurrence. Necropsy was not performed.

These men were regarded as identical twins by their family. Apparently they looked remarkably alike. The only objective evidence available is that they had the same blood group, i.e. O Rhesus-negtive. They lived together on the family farm in Central Lancashire until the age of 21 years in 1930 when they separated. Case 1 continued farming in West Lancashire until 1939 when he joined the Commandos. After World War II he worked as a chauffeur until retirement. Case 2 worked as aco grocer's delivery man until the war in which he also? joined the Services. After the war he worked in a wallpaper factory until his terminal illness. They had lived apart for 36 years when Case 2 developed his carcinoma.

\section{Discussion}

Kinship studies suggest that carcinoma of the stomach tends to occur more frequently in certain families (Maimon \& Zinniger, 1953; Videbaek \& Mosbech, 1954; Woolf, 1956; Cruze, Clarke \& El Farra, 1961). Militzer (1935) reported a pair of identical twin men in each of whom carcinoma of the stomach occurred within a few months. Gorer (1937-8) made an attempt to interpret twin cancer studies. He observed that tumours of the alimentary canal appeared to be influenced by genetic factors. Monozygotic twins resemble one another more closely than dizygotic twins of the same sex as far as localization and type of growth is concerned. Graham \& Lilienfeld (1958) reviewed the available evidence critically and pointed out the shortcomings of various pieces of evidence suggesting that there is a genetic basis for the occurrence of carcinoma of the stomach. In particular there was no study which was likely not to be biased in favour of finding a familial tendency since most reports were prompted 
by the discovery of a gastric carcinoma in the first place. In spite of these reservations they felt that the weight of evidence suggested that gastric cancer is concentrated in some families more than others. In an important twin study in Denmark, Hauge \& Harvald (1961) found that, as far as carcinoma of the stomach, colon and rectum are concerned, the rate of general concordance is about equal in monozygotic and dizygotic twins, but the rate of concordance as regards the site of the neoplasm is higher in the group of monozygotic than in the group of dizygotic twin pairs with carcinomata of the colonrectum.

Aird, Bentall \& Roberts (1953) showed that the frequency of blood group A is greater and that of group $\mathbf{O}$ is less in patients suffering from cancer of the stomach than in the general population and other workers confirmed this (Jennings, Balme \& Richardson, 1956; Beasley 1960). There is a high incidence of carcinoma of the stomach in patients with pernicious anaemia (Mosbech \& Videbaek, 1950; Hitchcock, MacLean and Sullivan, 1957). Shearman \& Finlayson (1966) considered that the apparent excess of blood group A patients is entirely due to the high incidence of gastric cancer in pernicious anaemia, in which condition there is also a preponderance of blood group A (Hoskins et al., 1965).

Maddock (1966) studied aetiological factors in cancer of the stomach in North Wales where the incidence is remarkably high. He concluded that the evidence suggested that specific environmental and exogenous factors were operative, powerful enough to obliterate evidence of the ordinary genetic factors. He noted a reversal of the usual blood group A predominance over blood group $\mathbf{O}$, no relationship to pernicious anaemia, a high proportion of elderly cases and an atypical distribution of site of origin of the tumours, all suggesting significant environmental influences. In contrast, Ashley \& Davies (1966) found that the highest frequency of the disease in Wales is seen in areas where Welsh is spoken most and there is an undue preponderance of Welsh names among such cases compared with a control group, strongly supporting the proposal that genetic influences predominate.

The observation that the mortality and probably the morbidity from gastric cancer are changing in different countries supports the suggestion that environmental influences are important. There has been a marked fall in incidence in the white population of the U.S.A. (Haenzel, 1958) and a smaller fall in England and Wales (Case, 1956) and a dramatic increase in Japan (Segi \& Kurihara, 1960) where the disease is very common. The possible environmental factors in the aetiology of gastric cancer are not known. The significance of fungal toxins is under review but there is as yet no certain evidence that these substances have been carcinogenic in man. Stocks \& Davies (1964) found that the zinc/copper ratio in the soil was consistently higher in gardens at houses where persons had just died of stomach cancer after a period of 10 or more years' residence than it was at houses where similar residents had died from non-malignant causes.

\section{Acknowledgment}

I thank the Medical Staff at the Royal Infirmary, Blackburn and colleagues at the Victoria Hospital, Blackpool for their co-operation.

\section{References}

Aird, I., Bentall, H.H. \& Roberts, J.A.A. (1953) A relationship between cancer of stomach and ABO blood groups. British Medical Journal, 1, 799.

Ashley, D.J.B. \& Davies, H.D.D. (1966) Gastric cancer in Wales. Gut, 7, 542.

BEASLEY, W.H. (1960) Blood groups in gastric ulcer and carcinoma. British Medical Journal, 1, 1167.

CASE, R.A.M. (1956) Cohort analysis of cancer mortality in England and Wales, 1911-54 by site and sex. British Journal of Preventive and Social Medicine, 10, 172.

Cruze, K., Clarke, J.S. \& El Farra, S. (1961) Familial aspects of gastric adenocarcinoma. American Journal of Digestive Diseases (New Series), 6, 7.

GORER, P. (1937-38) The genetic interpretation of studies on cancer twins. Annals of Eugenics, 8, 219.

Graham, S. \& Lilienfeld, A.M. (1958) Genetic studies of gastric cancer in humans-an appraisal. Cancer, 11, 945.

HAENZEL, W. (1958) Variation in incidence of and mortality from stomach cancer with particular reference to the United States. Journal of the National Cancer Institute, 21, 213.

Hauge, M. \& Harvald, B. (1961) Malignant growths in twins. Acta genetica et statistica medica, 11, 372.

Hitchсock, C.R., MacLean, L.D. \& Sullivan, W.A. (1957) Secretory and clinical aspects of achlorhydria as precursors of gastric cancer. Journal of the National Cancer Institute, 18, 795.

Hoskins, L.C., Loux, H.A., Britten, A. \& Zamcheck, N. (1965). Distribution of ABO blood groups in patients with pernicious anaemia, gastric carcinoma and gastric carcinoma associated with pernicious anaemia. New England Journal of Medicine, 273, 633.

Jennings, D., Balme, R.H. \& Richardson, J.E. (1956) Carcinoma of the stomach in relation to ABO blood groups. Lancet, ii, 11.

MADDOCK, C.R. (1966) Environment and heredity factors in carcinoma of the stomach. British Journal of Cancer, 20 (4), 660.

MaImon, S.N. \& ZinNiger, M.M. (1953) Familial gastric cancer. Gastroenterology, 25, 139.

Militzer, R.E. (1935) Carcinoma of the stomach in identical twins. American Journal of Cancer, 25, 544.

MosbeCh, J. \& VIDEBAEK, A. (1950) Mortality from and risk of gastric carcinoma among patients with pernicious anaemia. British Medical Journal, 2, 390.

Segi, M. \& Kurihara, M. (1960) Tohoku Journal of Experimental Medicine, 2, 170.

Shearman, D.J.C. \& Finlayson, N.D.C. (1967) Familial aspects of gastric carcinoma. American Journal of Digestive Diseases, 12 (5), 529.

Stocks, P. \& DAVIES, R.I. (1964) Zinc and copper content of soil associated with the incidence of cancer of the stomach and other organs. British Journal of Cancer, 18, 14. 
Videbaek, A. \& Mosbech, J. (1954) Aetiology of gastric carcinoma elucidated by study of 302 pedigrees. Acta Medica Scandinavica, 149, 137.
Woolf, C.M. (1956) Further study on familial aspects of carcinoma of stomach. American Journal of Human Genetics, 8, 102.

\title{
Subacute combined degeneration of the spinal cord in a vegan
}

\author{
H. N. MISRA \\ M.B., B.S.(Cal.), M.R.C.P.(U.K.)
}

\author{
J. M. FAllowfield \\ M.B., Ch.B.(Manchester)
}

Wythenshawe Hospital, Manchester

SUBACUTE combined degeneration of the spinal cord in nutritional vitamin $\mathbf{B}_{12}$ deficiency states, though a rare complication, has been reported several times (Badenoch, 1954; Wokes, 1956; Smith, 1962; Connor \& Pirola, 1963; Riley, 1966; Verjaal \& Timmermans, 1967), and its association with veganism (vegans are people who exclude all forms of animal products from their diet) has been duly stressed by Wokes (1956) and Smith (1962). Although vegans would appear to be highly vulnerable subjects for deficiency disease, in fact the incidence of manifest symptoms and signs due to vitamin $B_{12}$ deficiency is rare, even when the serum levels are well below the range found in pernicious anaemia (Smith, 1962). The reason for this anomaly is not clear, though Smith (1962) advanced the view that tobacco smoking in vitamin $\mathbf{B}_{\mathbf{1 2}}$ deficiency states plays a definite role in the genesis of neurological complications, and of his reported cases, the only two patients with subacute combined degeneration of the spinal cord were smokers.

We consider our patient unique in the sense that she was a vegan who was a non-smoker but nevertheless she developed subacute combined degeneration of the spinal cord.

\section{Case report}

Miss D. A., aged 62 years, was admitted to Wythenshawe Hospital on 6.10.69 under the care of Dr C. D. R. Pengelly for the investigation of unsteadiness of gait and stiffness of her lower limbs. Her symptoms had started gradually over a 3-year period with tingling of hands and feet. She had noticed that handling money was difficult because it felt like sandpaper. Subsequently her gait became progressively ataxic until she was house-bound. Eventually she had to hold on to furniture to remain upright. Ten days before admission she fell and sustained a left Colles' fracture. She dismissed this as a bruised wrist and sought no medical treatment. The consequent lack of mobility and pressure from her neighbours led to her admission to hospital.

There was no significant history of past illness. She had been a vegetarian since 1943 and for 5 years prior to admission she had been a vegan. She had been a non-smoker and teetotaller all her life.

On admission physical examination revealed no evidence of malnutrition and there was no pallor. Examination of the alimentary, cardiovascular and respiratory systems revealed no abnormality. BP $170 / 90 \mathrm{mmHg}$, routine urine examination normal. Examination of the nervous system was as follows: mentality normal; cranial nerves normal; there was no abnormality in the power, tone or reflexes in the arms; the lower limbs were slightly spastic, she could hardly stand on her feet and she was completely unable to walk without support; Romberg's sign was strongly positive; both ankle jerks were diminished; plantar responses on both sides were extensor; there was slight diminution of light-touch and pinprick sensation over feet and hands; vibration sense was completely absent up to the lower end of the sternum and joint sensation was grossly impaired in both lower limbs.

Investigations. $\mathrm{Hb} 10.5 \mathrm{~g} / 100 \mathrm{ml}, \mathrm{PCV} 34 \%$, MCHC $30 \%$, WCC $5000 / \mathrm{mm}^{3}$. Peripheral blood film: some macrocytes, normal differential count. RBC normochromic. Blood urea $35 \mathrm{mg} / 100 \mathrm{ml}$, midstream urine examination negative. Liver function tests normal. Serum protein levels: total $6 \cdot 5$, albumin $3 \cdot 2$, globulin $3.3 \mathrm{~g} / 100 \mathrm{ml}$. Serum vitamin $B_{12}$ levels on two separate occasions were 71 and $72 \mathrm{pg} / \mathrm{ml}$ respectively. Serum folate $16 \mathrm{ng} / \mathrm{ml}$. A bone marrow smear revealed megaloblastic erythropoiesis. A test meal showed the presence of free acid in the gastric juice. Faecal fat estimation on three successive occasions revealed normal values: $2 \cdot 7,1 \cdot 5$ and $3 \cdot 5$ 